\title{
Living on the Extreme Margin: Social Exclusion of the Transgender Population (Hijra) in Bangladesh
}

\author{
Sharful Islam Khan', Mohammed Iftekher Hussain',Shaila Parveen', Mahbubul Islam Bhuiyan', \\ Gorkey Gourab', Golam Faruk Sarker', Shohael Mahmud Arafat'르 and Joya Sikder ${ }^{3}$ \\ 'Social and Behavioural Sciences Unit, Public Health Sciences Division, ICDDR,B, GPO Box I28, Dhaka I000, Bangladesh, \\ 2Bangabandhu Sheikh Mujib Medical University, Dhaka I000, Bangladesh, and ${ }^{3}$ Badhan Hijra Sangha, \\ Kuril, Dhaka I229, Bangladesh
}

\begin{abstract}
The transgender people (hijra), who claim to be neither male nor female, are socially excluded in Bangladesh. This paper describes social exclusion of hijra [The term is used in this abstract both in singular and plural sense] focusing on the pathway between exclusion and sexual health. In an ethnographic study, 50 in-depth interviews with hijra, 20 key-informant interviews, and 10 focus-group discussions (FGDs), along with extensive field observations, were conducted. The findings revealed that hijra are located at the extreme margin of exclusion having no sociopolitical space where a hijra can lead life of a human being with dignity. Their deprivations are grounded in non-recognition as a separate gendered human being beyond the male-female dichotomy. Being outside this norm has prevented them from positioning themselves in greater society with human potential and security. They are physically, verbally, and sexually abused. Extreme social exclusion diminishes self-esteem and sense of social responsibility. Before safer sex interventions can be effective in a broader scale, hijra need to be recognized as having a space on society's gender continuum. Hijra, as the citizens of Bangladesh and part of society's diversity, have gender, sexual and citizenship rights, that need to be protected.
\end{abstract}

Key words: Hijra; HIV; Social exclusion; Bangladesh

\section{INTRODUCTION}

Transgender communities historically exist in many cultural contexts, known as bakla in the Philippines, xaniths in Oman, serrers among the Pokot people of Kenya, and hijra, jogappas, jogtas, or shiv-shaktis in South Asia. The hijra, also called 'third gender' or eunuch-transvestites, have existed for centuries in the Indian sub-continent $(1,2)$. They do not conform to conventional notions of male or female gender but combine or move between the two. Their vulnerabilities, frustrations, and insecurities have been historically overlooked by mainstream society. In Bangladesh, mainstream society does

Correspondence and reprint requests should be addressed to:

Dr. Sharful Islam Khan

Associate Scientist and Medical Anthropologist

Social and Behavioural Sciences Unit

Public Health Sciences Division

ICDDR,B

GPO Box 128

Dhaka 1000

Bangladesh

Email: sharful@icddrb.org not accept others beyond the male-female gender norm. Those who live beyond this continuum are subject to harassments and abuses.

The nationwide behavioural and serological surveillance in Bangladesh demonstrated the vulnerability of hijra [The term is used in this paper both in singular and plural sense] to sexually transmitted infections (STIs), including HIV, due to selling unprotected sex with multiple clients. The hijra in Dhaka, the capital city, had the highest recorded rate of active syphilis (10.4\%) among other most at-risk populations (3). These findings warranted immediate HIV interventions for them. Several non-governmental (NGOs) and community-based organizations (CBOs) implement HIV interventions primarily promoting condoms and lubricants and mainly providing treatment of STIs.

The hijra claim that mainstream society does not understand their culture, gender, and sexuality. Dimensions of their social deprivation and harassments to them have never received attention in development sectors. Violations of their human and sexual rights have been overlooked in the tradition- 
al HIV-intervention frameworks [Khan SI. Personal communication, 2007]. The CBOs do not provide any social or legal services to them in terms of establishing their citizenship rights. Sole promotion of condoms and lubricants ignores multidimensional ruptures and alienation that exist within any targeted population (Khan SI. Personal communication, 2007).

Understanding the sociocultural and human rights aspects of discrimination against the hijra community and deprivation can help reduce STI/HIV transmission and safeguard this marginalized community. International Centre for Diarrhoeal Disease Research, Bangladesh (ICDDR,B) undertook ethnographic research to understand and analyze the hijra culture with a focus on gender and sexual socialization process, adverse life-situations, discrimination, and abusive incidents. This paper analyzes the complex ways in which hijra experience deprivations using the framework of a dynamic, inter-relational and multidimensional model of the social exclusion theory.

\section{Social exclusion: concept and dimensions}

Use of the 'social exclusion' concept in the literature of Bangladesh (4), as in many regions (5), is recently becoming popular for its relevance to policy and practice $(6,7)$. Several definitions worth mentioning include: "Social exclusion is an accumulation of confluent processes with successive ruptures arising from the heart of economy, politics and society; gradually distances and places persons, groups, communities and territories in positions of inferiority in relation to centre powers, resources and prevailing values" (8). Beall and Piron suggest "a process and a state that prevents individuals or groups from full participation in social, economic and political life and from asserting their rights. It derives from exclusionary relationships based on power" (9). Thus, the excluder rejects social relations denying access to resources and services, violating citizenship rights to particular individual and groups.

Silver proposes three paradigms-solidarity, specialization, and monopoly-which are grounded in the economic, social, cultural and political context. These paradigms were in contexts of republican, liberal, and social democratic societies. Their relevance to Asian Muslim society has not been explored (10). Socially-excluded people or groups of people are not able to participate in societal mainstream activities. Factors contributing to social exclusion include poverty, non-dominant social identities, e.g. race, ethnicity, religion, and gender; social locations (migrants, refugees); demographic features (occupation, educational level); and health conditions, e.g. disability, stigmatized diseases, such as HIV and AIDS (7). Social, economic, cultural and political aspects of exclusion enforce deprivations of the basic amenities of life $(5,9)$.

The Social Exclusion Knowledge Network (SEKN) model, developed by Popay et al. assumes that social exclusion is driven by unequal power dynamics and operate in four interconnected and relational dimensions (e.g. cultural, economic, political, and social) at different levels (e.g. individuals, groups, households, communities, countries, and the world as a whole) (6). The power dynamics construct a continuum: inclusion to exclusion along the line of inter-related and interdependent factors, such as cultural, economic, political and social issues. Economic aspects of exclusion include barriers to employment opportunities, constrained access to commodities, and livelihood opportunities, such as income, housing, land, and working conditions. Social aspects of exclusion refer to limited or no access to social, educational, legal and health services, resulting from ruptured social protection and social cohesion, such as kinship, family, neighbourhood, and the community. Cultural aspects of exclusion refer to subordination of certain norms, behaviours, cultural practices, and lifestyles which exclude certain individuals or groups. Political aspects of exclusion refer to deprivations of citizens' rights, including restricted access to organizations, voter rights, legislations, constitutions, and decision-making in policy. This multidimensional model of social exclusion also frames analysis of the experiences of hijra. An explicit link between exclusion and rights encompasses discrimination on the basis of gender orientation. Many scholars described excluded groups as ethnic, religious and linguistic minorities, and disabled persons. Typically, elderly, migrants, refugees, domestic workers, women, illiterate people, and extreme poor people are also included $(5,7)$. However, transgender population or others who prefer living with alternative gender and sexualities are not included in the list. Gendered exclusion was only considered in the case of women in various settings. The paper has used the SEKN model to guide theoretical and conceptual exploration of social exclusion in lives of hijra.

\section{MATERIALS AND METHODS}

Ethnographic research methods were used for blending qualitative data-collection methods to obtain a detailed and reliable picture of the hijra 
community. We recognized members of the hijra community as experts capable of analyzing their own problems. We involved them in exploring and analyzing their experiences of marginalization. Through ethnography, 'tales from the field' were explored to gain multiple interpretations and perspectives of the hijra culture (11). Fifty in-depth interviews and 20 key-informant interviews were conducted. Key-informants included influential guru (a hijra leader who maintains a few disciples and is responsible to guide, control, and assist them in many ways in everyday life) and chela (disciples) of the hijra community, hijra sex workers, medical professionals working in CBOs to treat hijra, nonhijra professionals, such as teachers, researchers, programme managers, journalists, and community leaders and activists for transgender rights. Five lifehistory interviews were conducted with selected hijra to understand the sexual socialization and social exclusion processes in the life-cycle approach. In addition, 10 homogenous FGDs were conducted with hijra sex workers and others involved only in traditional hijra occupations, the guru, and hijra and non-hijra staff working for HIV interventions. Extensive field observations were conducted to understand the hijra culture, behaviours, rituals, sex trade, and other life conditions. We ensured active involvement of the hijra community in all phases of the project. The Ethical Review Committee of ICDDR,B approved the project.

Badhan Hijra Sangha and Shustha Jibon-the two CBOs operating HIV interventions with hijra in Dhaka city were involved to obtain valid, reliable information and to gain access to the community. Four hijra hired as staff members of ICDDR,B were involved in designing, field-testing, and finalizing interview guides, selection of samples, collecting data and interpreting findings, and creating supportive research environment.

We identified emerging themes and subthemes as appeared in textual data transcribed from the interviews and FGDs. Voluminous data were organized by careful, repeated, and systematic review of all transcripts linked to the research questions. Gaps and issues not previously considered were included in subsequent interviews. Prominent themes, logical connections, clarifications, and relevant comments that would match and/or assist in explaining similar statements were identified, and coding in atlas.ti showed emerging domains. The categorization process included identification of salient themes, recurring ideas, meanings and language, and logical relationships.
Conventionally, study subjects are not offered any role in the research process, particularly when collection of data is over. However, we encouraged some members of the hijra community to interpret meanings of data. This approach reduced subjective bias of the researchers, enhanced objectivity in analysis of data, democratized the research process, and empowered the hijra by endorsing their capacity in analyzing situations and proposing possible interventions.

Credibility and transferability of findings were achieved through the robustness of the research process and by integrating multiple data-collection techniques and inter-subjective interpretations. Our prolonged involvement (24 months) with the hijra community allowed for diverse and consistent information and a process of corroboration through interpretations by the researchers and participants. In-depth interviews facilitated the understanding of the complexities of lives of hijra expressed in their own terms. We incorporated opinions of key-informants for validating data collected from other sources. The research design, research process, and concepts used in this study can be used for comparative studies in other settings. Methods and theoretical propositions used in the research process can also guide similar studies with transgender people in other regional countries. Peer debriefing, participatory interpretations with participants, and inter-subjective understanding of findings among the members of the research team have contributed to the dependability of the findings presented in this article.

\section{RESULTS}

The hijra experience multiple dimensions of exclusion. Such experiences instigate negative health and rights outcome, particularly in terms of their vulnerabilities to STIs/HIV. In the following section, diverse but inter-related experiences are described to demonstrate social exclusionary pathways.

\section{Female psyche in male physic: nurtured for negligence}

Early childhood preference of a hijra for female clothing, make-up and attire, playing with girls rather than with boys, preferring household work culturally assigned for females, and possessing a 'soft' nature like girls, was not taken negatively by family members, particularly by mothers who enjoyed looking at 'soft' nature of their 'boys'. Other family members did make fun of these boys but only strongly opposing feminine behaviours dur- 
ing adolescence. Parents and other family members expected boys to portray 'boyish' images. When boys at adolescence did not fulfill their familial expectations, it became problematic. When informants being biological males continued to display meyeli shobhab (feminine attitude and behaviour) even in adolescence and adulthood, they encountered various types of negligence, humiliation, and abusive incidents.

'Unusual feminine development' of early childhood tarnishes the family image. Family members felt uncomfortable with feminine behaviours of their male adolescents, particularly when the family encounters negative and unpleasant societal experiences concerning to feminine attitudes and behaviours of their children. Incidents of social disapproval and rejections eventually influenced families to take up opposing roles. As feminine male adolescents, the hijra informants confronted discriminatory and conflicting behaviours in their homes. In many instances, feminine males were accused of creating societal 'problems'. Criticisms of neighbours and incidents of offensive teasing from neighbouring males often created unpleasant situations where parents felt offended. Feminine behaviours were initially nourished and nurtured, with time but were condemned and discouraged. The disapproval was raised by society but ultimately also by family. As feminine males, the informants reported to be devalued in families and received double standards and discriminatory behaviours compared to other 'normal' siblings in terms of food, clothing, schooling, and other opportunities.

\section{Humiliations in school: where to study?}

The 'unusual' growth of a feminine boy is not tolerated in schools where the informants often encountered a hostile environment for incompatible sex-gender roles and attitudes. They often experienced loneliness and abusive treatment; for example, they were not allowed to share with classmates, extending from the classroom to the playground. Feminine attitudes of the informants were matters of jokes and humiliation, as one hijra stated:

When I went to school, the classmates used to criticize me. They pointed me by saying, "he is a maigya pola (effeminate boy). He will end up as hijra. He cannot play with us. He cannot sit with us." They used to throw me out of the class. When I went to play with the boys, they did not accept me, and even the girls also did not want to play with me. Often I found myself sitting in a corner in the class or playground.

Most informants failed to find a safe space at school. Unable to adapt within hostile school environments, most became reluctant to continue schooling. Teachers abused them, shouting for change in their feminine behaviours. Influenced by predominant norms and values of society, teachers accused effeminate boys of violating school and societal 'decorum'. Some informants claimed to have secret sexual relations with their male teachers. Eventually, they could not stay in schools, resulting in discontinuation of education which ultimately diminished future employment opportunities.

\section{Identity crisis: who am I?}

Deprived from family and school environment, the informants reported that, as feminine boys, they were often told that their attitudes, bodygestures, and behaviours were unlike other boys. The informants became confused about their sex-gender alignment: "Am I a male, female, female mind in a male body, or a hijra?" Many hirja claimed to have a soul of a female trapped in a male body. One hijra described with metaphor, "Uportolai nayeeka ar nichertolai nayok" (actress at the top and actor at the bottom), which means the hijra have penis like men and and breasts like women to indicate that they are neither males nor females but a mix of both.

Many play a double-life in this dichotomous gendered society to avoid stigma and discriminations. They wear female clothes and adopt feminine names while visiting peers. However, they wear male clothes and adopt male gestures while living with or visiting relatives. Their feminine role is denied. They cannot avoid the dilemma of their identity crisis.

The informants reported that maintaining two different lifestyles in and outside the home created an identity crisis. A hijra is compelled to go through strenuous situations and struggles to be declared as a self-identified hijra in a society where it is seen as a curse. It is difficult for them to cross the boundary of male-female dichotomous gender norms and to find a healthy, safe, and peaceful space in this hetero-normative society. The informants reported that feminine emotions trapped inside a masculine body were ignored and denied. Hijra sexuality and sexual behaviours conflict with her biological sex, and her biological sex mismatches with her preferred feminine gender roles. Thus, the informants reported that conflicts relating to self-identity had diminished their human dignity and self-reliance. 
As a result, they claimed to be discouraged in practising safer behaviours to protect their lives from any unknown danger, such as HIV and AIDS.

\section{Living for leaving: where to go?}

Feminine attitudes quite often become the source of physical and psychological trauma. The hijra informants reported leading double-lives as young feminine males at home pretending to be masculine versus complete feminine with mental relief when with peers. They preferred wearing feminine garments not permitted in the home. In front of relatives, they were discouraged to show feminine attitudes. Exhibiting 'unwanted' and 'abnormal feminine behaviours', chances of marriage of their siblings become uncertain. As hijra, they were often excluded from family events, weddings, and funerals. As one hijra recalled:

When my father died I did not go to bury him. If I had gone there, the relatives and others would not take part in the burial. The Imam would not conduct the janaza (religious rite). I had very long hair, I used to wear a lot of jewellery and saree, then my relatives told me, "you are wearing gold like women, you should not touch your father's dead body."

Despite being connected to a family, a hijra is virtually alone. They tried to get attached to their parental homes at any cost to obtain mental relief but most often this generated more pain when they experienced rejection from their families. They often failed to manage a safe space inside their families.

At some point, they encountered extreme familial pressure to marry, to return to 'normal' life. However, most hijra informants claimed that they would not be able to marry and lead a family life with wives. Therefore, they regretted to accept the decision of marriage. With time, the adversities became so intense at home and outside that the feminine males had no choice but to leave families.

This decision of leaving home was finalized when they became closely associated with feminine male friends where they were fit psychologically, sexually, and socially. When a hijra met a hijra guru and became a chela of that guru, he found a place to live. Some hijra informants reported not even being sexually safe at gurus' homes as they were forced to have sex with men who paid money to guru. Being sexually and financially abused, most of them finally left gurus' homes. Not all hijra lived with guru, some rented rooms to live in isolation. They preferred to become a hijra by involving in hijra giri (traditional activities performed by the hijra). Many sold sex independently. They developed love relations with males whom they called parik. Some hijra lived together in groups resembling to a family life. Finding a safe living place was difficult as claimed by most informants. Most landlords did not rent rooms to hijra. House owners only provided them rooms, if they behaved 'properly'. Many hijra lived at slums with history of eviction. Some reported staying in parks or stations. Most hijra reported a 'homeless situation', although their parents and relatives had homes. Most were initially living with their families but after encountering various adversities, they had to leave home. They had to change living arrangements for an unending search for a suitable place where they could live safely and with dignity.

\section{Occupation: where to work?}

The hijra claimed inability of getting a mainstream job due to lack of education, 'unusual' non-conforming lifestyle unacceptable for the working environment. "We, because of our feminine gesture, do not have access to any job. We are always kicked out from the job on the grounds of 'destroying' the job environment." Some got jobs but eventually were dismissed when employers learned of their feminine attitudes. In some cases, many hijra were abused verbally, physically, and sexually at workplaces for which they never received any justice. They rather lost the job because the employers wanted to 'save the workplace from sexual pollution'. One hijra depicted 'her' condition when 'she' attempted work in a garment factory:

I have worked in a garment factory for about a year. I could not even go to the toilet, as I was scared that the boys would go there to see me. They always tried to have sex with me. When there was a night shift, the threat was higher. Once my supervisor forced me to have sex with him, and I had no choice to but to do it. But when it became public, my job was dismissed, as if it was my fault.

Most hijra informants expressed their desire to be involved in any occupation. However, they were denied in the job market. They were involved in hijra giri which referred to bazaar tola (collecting money from the market place) and badhai (blessing a newborn child through dancing and singing). Traditional hijra occupations are constrained in many ways. For example, badhai became difficult, particularly in urban areas, and in rural areas, even if allowed, finally they were refused to be paid 
at the end of performance. These constraints influenced them in making rude remarks followed by tin tali (traditional clap) and lifting up sarees to show their 'castrated' genitals in public. Such behaviour compels the mainstream society to identify them as 'unusual', treating them as social outcasts. With more urbanization, modern markets are now protected by securities for which they cannot enter such markets. In the current context of economic recession, the hijra informants reported difficulties in collecting money from small shops as they used to do earlier. In this context, many hijra started to be involved in selling sex. "Like me, many hijra now sell sex as it is economically profitable." A group of hijra sex workers stated in a similar voice: "now we survive by selling our own body". However, involving in sexual encounter was problematic for hijra, particularly because the greater society perceives them as 'asexual outcast', i.e. having no sexual organs; therefore, their involvement in sex trade makes them further stigmatized. This is not the ending; even after engaging in the sex trade, the 'asexual' hijra become further marginalized by own community for being sexually exposed in front of the greater society.

Hijra who work as sex workers often face sexual harassments by forceful unprotected sex. The hijra sex workers were exploited by clients, mugged, and beaten by hooligans but never received any police support. They hardly reported any incidence to police because of fear of further harassments. The law-enforcing agents either raped a hijra sex worker and/or burglarized earning from sex trade. Experiencing these threats, a hijra sex worker described experiences echoed in many others' voices as well:

Even hijra are not safe in sex trade. They are forced to have unprotected sex with clients, local influential persons, and police free of charge. Like my friends, now I also think that I should leave sex trade but where should I work, how to earn, and how to survive? I am so unfortunate; we, the hijra, better die but then after our death, our bodies will create problem in my family! How unfortunate!

A few hijra have been working in CBOs/NGOs and involved in HIV interventions for hijra and males having sex with males (MSM). They even reported unpleasant incidents, for example, being abused by the law-enforcing agents for bringing condoms, lubricants, and dildos during outreach services. Some were roughly treated by their own management. Some experienced repulsive behaviours when visiting offices of partner organizations because of their misfit to the bi-gendered organizational environment. "When I visit other offices, I get shaky and scared about the reaction of others. I have to wear nice dress because, who knows, someone may accuse me of violating the decorum of their office?"

\section{Love relations: whom to love?}

Most hijra described love relations with their male sexual partners. In many cases, attractions continue as that man also treats and compares 'her' with a woman. This temptation allows a hijra to take the economic burden of 'her' parik (male lover), with an ultimate hope that the parik will stay with 'her'. Most often men pretend to be in love-affair with the hijra and continue to have sex. In hetero-normative Bangladesh society, male-female sexual and marital relationship is obligatory because of compulsory fatherhood. A family life with a hijra perceived as neither male nor female, and unable to procreate is prohibited under sociocultural, religious and political rules and customs. At some point, such love relationships disappear. Society does not permit any transgressive relationship beyond hetero-normativity. A love relationship with a parik ends up with heart-breaking incidents. Sometimes, a parik snatches valuables while leaving a hijra. Finally, a hijra has hardly anyone to love or to live with. Hijra are aware of this uncertainty of transitory nature of love and risk of HIV infections but keep looking for other men to love for sexual acts, mostly unprotected. This may be the reason for keeping multiple pariks and sex partners for most hijra we interviewed. Although hijra and their male partners were aware of HIV transmission, their pariks had sex with them without condoms. Hijra could not pursue protected sex as condoms become the icon of mistrust. Therefore, hijra cannot insist on condoms as this may destroy the love relationship. Despite their honest efforts, they cannot retain a parik.

Sexual abuse and physical harassment: where is safety?

Most hijra described first sexual intercourse experiences at the age of 8-12 years. The first sexual relationship in most cases was developed with male relatives, neighbours, or lodging tutors. Most of these incidents occurred by force and were unprotected, putting them at risk of transmission of STI/HIV. In some cases, they were offered tangible benefits for making 'it' secret. After the first incident of such abusive sex, they felt ashamed and were frightened due to fear of disclosure in the family. With such repeated incidents, as reported, a boy generally became concerned about his feminine psyche: a mis- 
fit to societal norm and practice. Later on, due to feminine behaviours, they reported encountering serial harassments, beginning at home, extending, and unfolding to all spheres of life. Feminine boys were abused at schools, resulting in discontinuation of studies. Many were abused at workplaces, eventually ousted from jobs. Most involved in hijra giri or sex trade were again harassed verbally, physically, and sexually. Wherever or whenever these incidents had taken place, they could not disclose to anyone and sought support. Not the perpetrators, rather hijra were accused and punished in most cases. As a result, their human dignity and self-esteem were diminished. They reported feeling worthless and unfit to family and society. This was reflected in the voice of a middle-aged hijra:

We bring shame for our family; we cannot do anything good for society; we live in an extremely bad life-condition; we are abused and harassed all the time; and we are treated as strangers in this society. Our life is no better than that of an animal. Whether we survive or die, no one cares and no one bothers, and we also do not care for anyone. We know, in this world, we have no relatives or friends. We do not care for our survival.

By losing self-esteem and hope of survival as reflected in the above quotation, they became desperate and did not hesitate to be involved in various risky activities, including sexual acts and alcoholism.

IIIness of the hijra: where to seek healthcare from?

Access of hijra to healthcare services is constrained due to marginalized social status. If hijra suffered from anal STIs, they could not disclose it to doctors. Not only for STIs, because of holding stigmatized hijra identity, they had no access to health facilities. They reported hiding their identity while visiting doctors whether in government or private sectors. They were not allowed to seek healthcare at the private chambers of doctors no matter whether they could pay the doctor's fee or not. "Their presence may create fear and discomfort for other patients", claimed by a private medical practitioner in Dhaka city. This reality was reflected in a hijra guru's voice as well:

If the hijra suffer from health problems and go to the government hospitals, they receive abusive behaviours from the staff, including the doctor. If they suffer from STIs, it is virtually impossible to disclose it to the doctor. Generally, they have no choice but to get self-treatment or treated by traditional health practitioners. However, they can now go to the clinic operated by Badhan (a CBO) working for HIV prevention. Their doctors are good but sometimes they also behave badly.

Health facilities sensitive to the hijra culture are almost non-existent in Bangladesh. Medical doctors have limited knowledge about the hijra culture and sexuality. Our medical doctor interviewed showed his inadequate understanding about culture, gender, and sexuality of the hijra, being judgemental and even frightened to treat hijra patients. Our findings demonstrate extreme unavailability of health facilities for hijra.

\section{Ageing or death: where is the end?}

Old age is perhaps the most critical phase of the life-cycle of a hijra. This is more problematic for the hijra with no familial connections. A hijra sex worker cannot operate sex trade at old age. Shifting occupations is not easy. Survival becomes more difficult with ageing. For hijra who were primarily involved in badhai, the situation appeared even worse. Badhai occupation requires hard labour. At old age, being unable to work hard, despite the guru-chela hierarchy, guru reported not getting shares from badhai. We met a renowned hijra guru who was passing 'her' days in vulnerable situations. Most of 'her' chelas were reluctant to give 'her' a financial share. We saw 'her' fighting against death in social isolation. Many hijra could not return to their families. They stayed outside home and had no choice but to struggle against illness, poverty, and loneliness. Old age brings new and terrible threats for survival in the lives of hijra.

Most hijra live with frustrations and incidents of abuse and humiliations throughout their life. Ironically, death also cannot either guarantee a space, nor can it terminate the endless disgrace. With death, everything ends besides the pain of the life of a hijra. Death initiates another critical chapter of abuse and dishonour for the dead bodies.

According to many hijra, the dead body of a hijra cannot be buried normally due to multiple societal and religious resistances. If a local religious leader knows that the dead is a hijra, he often refuses to complete the religious rituals relating to the funeral. This is embarrassing for the family for becoming humiliated. That is why the family members try to hide the identity of a hijra and arrange the namaz$e$-janaja (prayer at funeral) as a male member of the 
family. The situation becomes more problematic in the case of a castrated hijra. This is because the chance of disclosing the identity is high as people involved in preparing the dead body for the funeral (e.g. bathing of the body, dressing white cloth before burial in the cemetery) can see the castrated genitals. If this becomes public, no one will participate in the funeral. In many cases, the news of death of a castrated hijra is kept hidden, and only some close associates complete the funeral secretly. We were told of an incident where, during namaze-janaza, some religious leaders and influential persons forced the Imam (the head of a mosque) to stop the prayer. Another case was reported where the dead body was denied burial in the gorosthan (cemetery for Muslims), rather the dead body was thrown out into the river.

Hijra suffer from unbearable pain and humiliations while they are alive. Struggles for space do not end with death. After death, their bodies are not treated with honour. Their hijra identity created problems even after death. The society, religion, and the state fail to ensure honour to the departed soul of a human being. They encounter multidimensional problems relating to their space in society while they are alive; even after death, the crisis of societal space has not ended.

\section{The state: resilience or resistance?}

Hijra are excluded from familial and social life and are equally excluded from the state. In all official forms of educational institutes, various service organizations, banking sectors, citizenship forms, birth certificates, passports, and voter identification cards, sex (or gender) is shown as a rigid bivariate category. Thus, a hijra must identify as a male or a female, otherwise their fundamental citizenship rights will not be granted under any other category. In this way, the state has imposed gender on any population, including the hijra, ignoring the fact that gender is socially constructed, diverse, and fluid in nature. Keeping the hijra identity, they cannot even inherit family properties. A CBO activist pointed out the failure of the state in the following manner:

The state has the sole responsibility to protect and uphold the human and citizenship rights of every citizen. Hijra are born citizens of Bangladesh. They cannot be discriminated against based on their preferred gender and sexual orientation. The Constitution of Bangladesh, so far as I know, does not discriminate against any human being based on sex, gender, race, caste, or religion whereas hijra are deprived from ev- ery citizenship rights. The state has completely failed to protect their rights. The state itself has rather violated their rights by bracketing them under male-female category. Gender cannot be imposed as it is a social construct, and for this reason, deprivations of women are intervened under the banner of gender issues, then why is the state silent in the case of hijra? Under which gender understanding are hijra alienated? Rather than resilience, the state is resistant in terms of mainstreaming us with health and development initiatives.

\section{DISCUSSION}

\section{The hijra: most excluded of the excluded}

Non-hijra members of mainstream society refuse to develop social relations with the hijra. On the other hand, they prevent access of hijra to social institutions, resources, and services. Powerless hijra cannot participate in social, economic, cultural and political activities, nor are they associated with the mainstream social systems and institutions, including health, supporting Beall and Piron's (2005) description of social exclusion as a process and a state (9). They are dominated and abused by the members of mainstream society, are unable to exercise power or to establish citizenship rights at home or in society. Access to social, cultural, educational, legal and health services is extremely restricted from anyone with a hijra identity.

The lives of hijra also fit into the three paradigms, i.e. specialization, solidarity, and monopoly, proposed by Silver (10). For example, because of individual behaviours, lifestyles, and practices, a hijra cannot participate in various social exchanges fitting to specialization framework of exclusion. Although solidarity among the hijra is quite strong, they as a group are excluded from the rest of society because of specific cultural conventions and group norms. They are considered 'abnormal' and eventually become 'outsiders', and finally because of situating at the lowest level in a hierarchical social structure, their access to materials and services is constrained, resembling Silver's monopoly framework of exclusion.

Multiple patterns of social exclusion in the lives of hijra can be applied to the framework of multidimensional social exclusion proposed by many scholars $(9,10)$. According to the SEKN model of social exclusion (6), hijra are excluded socioculturally (e.g. discrimination, humiliation, and deprivations at home; excluded from own home, school, 
and employment settings; and rituals surrounding death), politically (e.g. constrained access to service facilities, including health, social and legal matters, deprivations from rights of the citizenship to voting power and rights to enlist as a hijra gender beyond male-female dichotomy), and economically (e.g. deprivation from earning livelihood from mainstream occupations).

The pattern and levels of exclusion in the lives of hijra validate the multidimensional model of social exclusion and demands further elaboration. The different dimensions of social exclusion presented by the SEKN are not mutually exclusive. Social, cultural, economic and political dimensions closely intermingle with each other in an integrated manner, exerting a collective exclusionary force in the lives of hijra. The findings of the present study demonstrate that deprivations, alienations, and hostilities encountered by hijra since early childhood are so intense and extreme that, at some point, finding no other social space, they exclude themselves-a status termed 'self-exclusion' (7). Self-realization and experiences of being excluded cannot be ignored while analyzing and measuring social exclusion of any population.

They postpone attempts at inclusion in society through their involvement in activities and lifestyles (e.g. hijragiri) in which they continue to be isolated as social outcasts. Although the multidimensional model includes many factors, the lives of hijra reveal some other dimensions of exclusion. For example, hijra pass their whole life in search of love in a sustainable relationship; Because of transient nature of love, they have no choice but to find one partner after another, each time with new hopes of sustainability. In this silent way, they are emotionally cheated and abused and, finally, cannot have a steady male partner. This can be described as a form of exclusion from love and faith at the extreme.

The socially-deprived lives of hijra demonstrate that gender has been inadequately taken into consideration in the broader framework of social exclusion. Gender is included in the social and cultural dimensions of social exclusion. Available literature on social exclusion has analyzed gender inequality as the basis of exclusion and has primarily focused on women (12). Gender incongruity is the basis of inequality and inequity in social and developmental indicators. Many government and nongovernment sectors have taken a gender-sensitive approach in their organizational culture to reduce physical, sexual, organizational and gender-based harassments. Nevertheless, gender is considered from a deficit perspective of male and female. In most cases, gender is meant as a woman's issue, and gender-based harassment means abuses committed by men against women. Gender-equality policies of most organizations primarily focus on interest of female staff and do not recognize the transgender people (13).

Our findings signify that most deprivations in the lives of hijra are grounded in non-recognition of a $h i$ jra as a separate gendered human being beyond the male-female dichotomy. This has prevented them from positioning themselves in the greater society with human potential and dignity. We suggest that gender can be taken as a core variable of social exclusion as gender-based deprivations and alienations often trap every human being in different times and spaces. Social exclusion on the basis of gender in the lives of hijra draws attention in social policy dialogue, particularly in the era of 'gender' when not surprisingly we limit our analysis of gender-based deprivations with the male-female dichotomy. The understanding of gender-based inclusion and exclusion is developed in the context of segregation into seemingly obligatory sex and gender-roles: males as agents of power to impregnate females and agents of economic and political productions, and females as agents of reproduction, child-rearing, and serving men as subordinate. In this polarization, although marginalization of women is widely acknowledged in most societies, they are not, however, excluded. The hijra, neither male nor female, who are distorting normativity, are located outside the bipolar gendered society. Thus, hijra are extremely excluded, particularly because of moralistic standpoints regarding gender and sexualities of the mainstream society where diversity is synonymous with deviation and deprivation.

The rigidity of the bipolar gender category is so intense that it limits the possibility of alternative spaces for those who do not conform to the gender norms of the mainstream society. Social exclusion is conceptualized as a continuum between inclusion and exclusion (6); however, hijra are never allowed to move along the range of exclusion to inclusion in their life-cycle. Even death cannot guarantee inclusion of a hijra in the cemetery. Thus, we argue that hijra are located at the extreme pole of exclusion, and this challenges the concept of the inclusion-exclusion continuum.

Social exclusion, risk-behaviours, HIV interventions, and human rights: a paradigm shift

In the SEKN model, a pathway between exclusion 
and health inequalities is 'both constitutive and instrumental' (6). In line with the SEKN proposition, the experience of constrained access to economic, social, political and cultural resources leads to negative impacts on health and well-being of any excluded populations, i.e. constitutive. On the other hand, limited participation may result in various other deprivations leading to ill-health, i.e. instrumental. By applying the SEKN model, we have attempted to analyze the link between social exclusion and HIV risk in the lives of hijra to contribute to the formulation of policy guideline.

The findings revealed no safe sociopolitical space where a hijra can lead a life of a human being with dignity. Some hijra reported suicidal attempts in a situation described as 'palabar jaiga nai' (nowhere to run). Because of constrained participation in family, social and public spheres and because of their extremely limited access to information and healthcare services, they delay seeking care for STIs, have low knowledge on prevention of HIV, do not use condoms, and suffer more from STIs. This is the constitutive pathway that links social exclusion to health problems (6).

This restricted level of participation and resultant exclusion in the lives of hijra eventually diminish their self-esteem, demolish human dignity, and erase their belongingness to society. They become frustrated and find themselves useless for society and, with limited opportunities, are encouraged to pursue a risky life-style that includes unprotected sex. This pathway was named instrumental linking social exclusion and health sufferings (6). On another dimension, hijra are harassed, in most cases, due to public exposure of their 'inappropriate' gender and sexual roles which are judged against normative gender and heterosexual dimensions of society in Bangladesh. These are clearly violations of human rights against sexual minorities (14). The incidences of harassment further compel them to pursue risky life-styles conducive to HIV transmission (15).

We argue that the current popular model of HIV intervention for hijra which has disregarded the multidimensional exclusion and only included condom and lubricant promotion and STI treatment is a mechanistic framework of intervention. By not addressing the narrow and inappropriate outlook of the greater society regarding gender and sexual diversities, by not challenging judgmental and damaging stance of policy planners and moralistic politicians in terms of not recognizing sexual rights of the sexual minorities, in the era of AIDS, research and interventions have divulged cultural practices and lifestyles of many stigmatized populations to provide HIV interventions. Without deconstructing rigid gendered social structure and social systems, only superficially dealing with transgender people is a dangerous endeavour. Even non-compliance to safer sexual behaviours cannot be intervened effectively if organizations do not attempt to mainstream hijra, along with men and women in society. Similar arguments were made in the case of MSM in other parts of the region (16).

Issues relating to gender and sexualities in the lives of hijra are deeply grounded in the context of poverty, discrimination, and violations of human and sexual rights. Not recognizing gender and sexual identities of hijra, their stigmatized sexual behaviours, access to basic human rights which include health, education, housing, and occupational opportunities, put their lives at risk. Any work for the hijra community must be designed in the health and human rights framework. Thus, a paradigm shift is needed where HIV interventions enhance the dignity and quality of lives of hijra to protect their basic human, sexual and gender rights beyond the framework of disgrace, disease, and death. We recommend that interventions need to create a space to challenge the sociopolitical and socioreligious discourses of sex and gender relations in society in Bangladesh.

The hijra are human beings with a full range of human dignity and potential. To this point, the state has not taken any responsibility to initiate a dialogue to acknowledge gender diversity beyond the male-female dichotomy. Most countries, with conservative and homophobic attitude towards sexualities and gender diversities, have outlawed people who do not align with obligatory heterosexuality and/or with male-female gender alliance. Negotiating marginalization to begin mainstreaming of hijra is a challenging endeavour. Nevertheless, this journey has to be instigated.

Currently, some efforts in terms of HIV interventions are being operated by two CBOs. The members of the hijra community are attempting to unite to raise their voices. Nevertheless, because of the legal, religious and political complexities, the movement of the hijra community alone is deficient. The work has to be done with the members of the mainstream society, particularly with the policy planners, civil society, and gatekeepers who generally exclude them at the structural level of the state. Unless the mainstream society is on board with an action-oriented realization, efforts of CBOs may remain unsuccessful. One may argue that, by putting 
hijra at the extreme of the exclusion continuum, we are further stigmatizing them. However, by exploring their life conditions and by putting them in an exclusion framework of analysis, we are initiating a dialogue for policy reforms regarding gender issues in Bangladesh.

Movement in favour of the transgender community must be initiated by the policy planners of the government and non-government sectors. The ultimate target is to ensure a supportive and congenial environment where, along with men and women, hijra, as citizens of Bangladesh, can live fulfilling lives by upholding their human, gender, and citizenship rights. This article corroborates the voice of a leader of a CBO: "we envision an 'inclusive' society where we are socially, culturally, economically, emotionally, religiously, and politically included."

\section{ACKNOWLEDGEMENTS}

This article is based on data of a project conducted at ICDDR,B with research grants (No. 00367) from the Department for International Dvelopment (DFID). The authors thank the Social and Behavioural Sciences Unit (SBSU) of the Public Health Sciences Division for their support to the project. All project staff members are to be thanked for their hard work. Special thanks to Dr. Heidi Bart Johnston for her very useful and valuable review. The authors are also grateful to Dr. Alejandro Cravioto (Executive Director), Dr. Abbas Bhuiya (Head of SBSU), and Dr. Tasnim Azim (HIV Programme Head) for their encouraging and supportive role throughout the project period which made possible to implement this kind of project with stigmatized people in the context of Bangladesh. Finally, the authors express thirs gratefulness to the members of the hijra community who provided their valuable time and shared intimate issues of their lives.

\section{REFERENCES}

1. Nanda S. Neither man nor woman: the hijra of India. 2nd ed. Belmont, CA: Wadsworth Publishing, 1999:196.

2. Reddy G. "Men" who should be kings: celibacy, emasculation and reproduction of hijra in contemporary Indian politics. Soc Res 2003;70:163-70.

3. Bangladesh Ministry of Health and Family Welfare. Directorate General of Health Services. National AIDS/STD Programme. National HIV serological and behavioural surveillance, 2002; fourth round technical report. Dhaka: National AIDS/STD Programme, Directorate General of Health Services, Ministry of Health and Family Welfare, Government of Bangladesh, 2004:110.

4. Johnston H. Disentangling inequities in Bangladesh: a social exclusion and health analysis. Background paper for Social Exclusion Knowledge Network. Dhaka: International Centre for Diarrhoeal Disease Research, Bangladesh, 2008:3-6. (SEKN background paper no. 11).

5. de Haan A. Bibliographic review on social exclusion in South Asia. Chapter 1. In: de Haan A, Nayak P, editors. Social exclusion and South Asia: a regional bibliographical review, the case of India. Geneva: International Institute for Labour Studies, 1995. (http:// www.ilo.org/public/english/bureau/inst/papers/1994/ dp77/ch1.htm, accessed on 20 August 2008).

6. Popay J, Escorel S, Hernández M, Johnston H, Mathieson J, Rispel L. Understanding and tracking social exclusion: final report to the WHO Commission on Social Determinants of Health. Lancaster: Social Exclusion Knowledge Network, 2008:207.

7. United Nations. Theoretical concepts of social exclusion. Chapter 1. In: Literature review on social exclusion in the ESCWA region. New York, NY: United Nations, 2007:2-7.

8. Estivill J. Concepts and strategies for combating social exclusion: an overview. Geneva: International Labour Office, 2003. $131 \mathrm{p}$.

9. Beall J, Piron L-H. DFID social exclusion review. London: Overseas Development Institute, 2005:32-7.

10. Silver H. Social exclusion and social solidarity: three paradigms. Int Labour Rev 1994;133:531-78.

11. Van Mannen J. Tales of the field: on writing ethnography. Chicago: University of Chicago Press, 1988:127.

12. United Nations Development Programme. The Arab human development report 2005: towards the rise of women in the Arab world. New York, NY: Regional Bureau for Arab States, United Nations Development Programme, 2006:313.

13. International Centre for Diarrhoeal Disease Research, Bangladesh. Towards gender equality: ICDDR,B gender policy. 2nd ed. Dhaka: International Centre for Diarrhoeal Disease Research, Bangladesh, 2006. 24 p.

14. Joint United Nations Programme on HIV/AIDS. International guideline on HIV/AIDS and human rights: 2006 consolidated version. Geneva: United Nations High Commissioner for Human Rights, 2006. 120 p.

15. Anyamele C, Lwabaayi R, Nguyen T-V, Binswanger $\mathrm{H}$. Sexual minorities, violence and AIDS in Africa. 2005. (Africa region working paper series no. 84). (http:// www.worldbank.org/afr/wps/wp84.pdf, accessed on 20 August 2008).

16. Samuels F, Verma RV, George CK. Stigma, discrimination and violence amongst female sex-workers and men who have sex with men in Andhra Pradesh. Chapter 6. In: Valk M, Cummings SJR, van Dam H, editors. Gender and health: policy and practice: a global sourcebook. Oxford: Oxfam Publishing, 2006:184. 